Case Report

\title{
Calcifying Odontogenic Cyst with Extensive Areas of Dentinoid: Uncommon Case Report and Update of Main Findings
}

\author{
Hellen Bandeira de Pontes Santos $\left(\mathbb{D},{ }^{1}\right.$ Everton Freitas de Morais ${ }^{D},{ }^{1}$ \\ Deborah Gondim Lambert Moreira, ${ }^{1}$ Luis Ferreira de Almeida Neto, \\ Petrus Pereira Gomes, ${ }^{2}$ and Roseana de Almeida Freitas $\mathbb{D}^{1}$ \\ ${ }^{1}$ Postgraduate Program in Oral Pathology, Federal University of Rio Grande do Norte, Natal, RN, Brazil \\ ${ }^{2}$ Oral and Maxillofacial Surgery Residence, Federal University of Rio Grande do Norte, Natal, RN, Brazil \\ Correspondence should be addressed to Hellen Bandeira de Pontes Santos; hellenbps@hotmail.com
}

Received 16 February 2018; Accepted 5 April 2018; Published 10 May 2018

Academic Editor: Stefan Pambuccian

Copyright (C) 2018 Hellen Bandeira de Pontes Santos et al. This is an open access article distributed under the Creative Commons Attribution License, which permits unrestricted use, distribution, and reproduction in any medium, provided the original work is properly cited.

\begin{abstract}
The calcifying odontogenic cyst (COC) is a benign odontogenic cyst that occurs in the gnathic bones. This cyst is part of a spectrum of lesions characterized by odontogenic epithelium containing "ghost cells," which may undergo calcification. Areas of an eosinophilic matrix material compatible dentinoid also may present adjacent to the epithelial component. However, these areas of dentinoid commonly do not appear so abundant in COCs. In this study, we report a case of intraosseous COC with extensive areas of dentinoid and perform an update regarding the clinical, radiographical, histopathological, and differential diagnosis, treatment, and prognosis of this cystic lesion.
\end{abstract}

\section{Introduction}

The calcifying odontogenic cyst (COC) was first described by Gorlin and colleagues in 1962 [1], which described a cyst lined by an ameloblastoma-like epithelium that contained variable amounts of ghost cells and calcifications. This cyst is not common in the gnathic bones, representing about less than $6 \%$ of all odontogenic lesions $[2,3]$.

Recently, this lesion was reclassified as a cystic lesion again by the World Health Organization (WHO) [4]. It was showed in an international collaborative study that just under $90 \%$ of these lesions are either entirely cystic or associated with odontomas [5]. For this reason, the WHO's group believe that there is no justification for classifying these lesions as neoplastic [6].

COCs represent a heterogeneous group of lesions that show a variety of clinicopathologic and behavioral features [7]. Intraosseus COCs commonly occur with similar frequency both gnathic bones and majority of cases are found in the incisor and canine areas [8-10]. Radiographically, these lesions are usually an unilocular, well-defined radiolucency, although the lesion occasionally may appear multilocular. Radiopaque structures within the lesion, either irregular calcifications or tooth-like densities, may also be present in some cases [8-11].

The distinct feature of COC is a cystic lining demonstrating "ghost" epithelial cells with a propensity to calcify. This cyst most commonly occurs as a well-defined cystic lesion with a fibrous capsule and a lining of odontogenic epithelium with Ameloblastomatous appearance [10, 11]. Areas of an eosinophilic matrix material that are considered by some authors to represent dentinoid also may be present adjacent to the epithelial component. This is believed to be the result of an inductive effect by the odontogenic epithelium on the adjacent mesenchymal tissue $[10,11]$. However, to the best of our knowledge, these areas of dentinoid commonly do not appear so abundant in COCs. Herewith, we report a case of intraosseous COC with extensive areas of dentinoid and perform an update regarding the clinical, radiographical, histopathological, and differential diagnosis, treatment, and prognosis of this cystic lesion. 


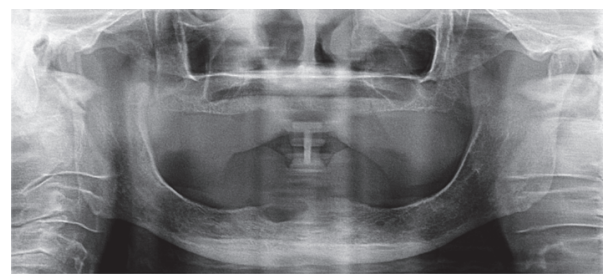

FIGURE 1: Panoramic radiography showing an unilocular radiolucent lesion in anterior mandible.

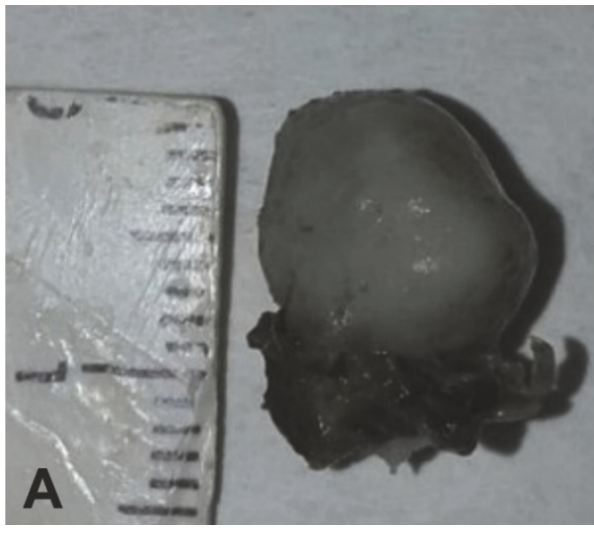

(a)

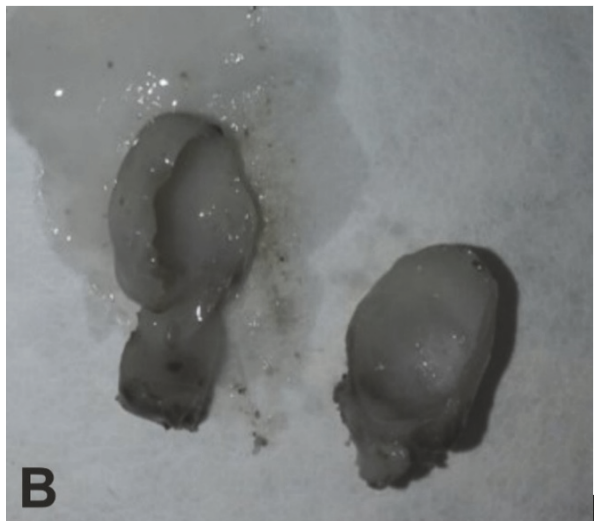

(b)

FiguRE 2: Gross aspect revealing a firm and oval mass with cystic aspect (a), containing liquid in the interior (b).

\section{Case Report}

An 82-year-old male patient presented in the Oral and Maxillofacial Surgery Service of the Federal University of Rio Grande do Norte for evaluation of a swelling on the alveolar ridge of the anterior mandible, which had been previously identified in routine radiographic examination with prosthesis purposes. During anamnesis, the patient reported to be hypertensive and diabetic, as well as having chronic heart disease. At the clinical examination, no volume could be observed in the anterior region of the mandible, and the patient reported no painful symptomatology.

Radiographical examination revealed an unilocular and irregular radiolucent lesion, measuring approximately $3 \mathrm{~cm}$ in diameter (Figure 1). Preoperative laboratory tests (hemogram, coagulogram, and blood glucose testing) were performed, as well as surgical risk and preanesthetic evaluation. Under the diagnostic hypothesis of residual cyst or another odontogenic lesion, the patient underwent surgery under general anesthesia in order to enucleate the lesion. In the transoperative period, in addition to surgical enucleation, a peripheral osteotomy and interposition of synthetic material for guided bone regeneration (Bio-OSS and Bio-Gide) were performed, considering the need for prosthetic rehabilitation of the patient. After the procedure, the specimen was sent to histopathological examination. Gross examination of the specimen revealed a firm and oval mass with cystic aspect, containing liquid in the interior (Figures 2(a) and 2(b)). Microscopically, the hematoxylin and eosin ( $\mathrm{H}$ and $\mathrm{E})$ stained section showed a defined cystic lesion with a fibrous capsule and a lining of odontogenic epithelium (Figures 3(a)-3(c)). The basal cells of the epithelial lining were mainly columnar and similar to ameloblasts and the overlying layers were loosely arranged, resembling the stellate reticulum of the enamel organ. Several amounts of ghost cells were found within the epithelial component and also in the capsule (Figure 3(c)). Extensive areas of eosinophilic matrix compatible with dysplastic dentin (dentinoid) were found in the fibrous capsule (Figures 3(d)-3(f)). After six months, bone neoformation has been observed and there has been no clinical or radiographic evidence of recurrence (Figure 4). The patient remains under follow-up.

\section{Discussion}

The COC is a rare entity of uncertain pathogenesis; its clinical and radiographic characteristics are not pathognomonic, being characterized mainly by its histopathological characteristics [12]. This cystic lesion is generally asymptomatic, and its radiographic features usually include an unilocular radiolucent lesion with focal areas of radiopacity [13]. However, it can occur also in extraosseous regions, as in the gingiva, corresponding to 15 to $25 \%$ of all reported cases of COC $[4,12,13]$.

Since its recognition and description by Gorlin et al. (1962) [1], the biological behavior of the COC is still a subject of much debate. According to the current classification of odontogenic tumors by the WHO, this lesion, which was previously known as calcifying cystic odontogenic tumor, has now returned to be considered a cystic lesion [4]. 


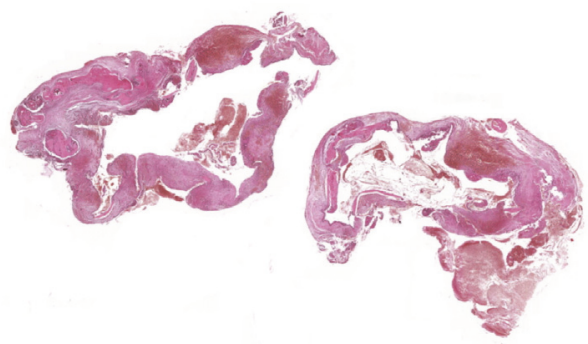

(a)

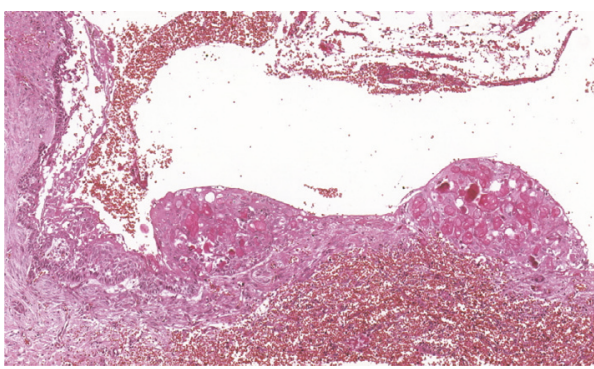

(c)

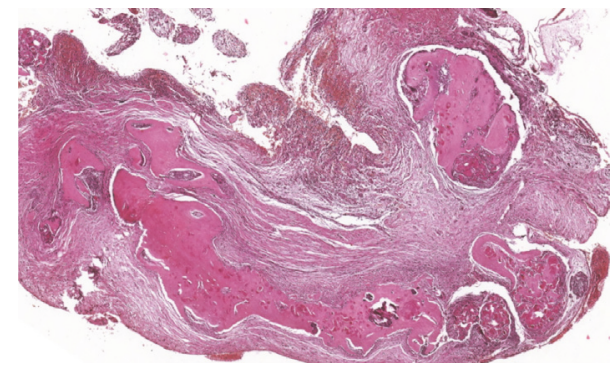

(e)

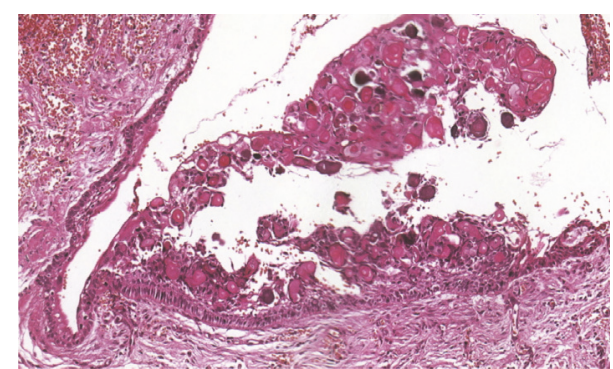

(b)

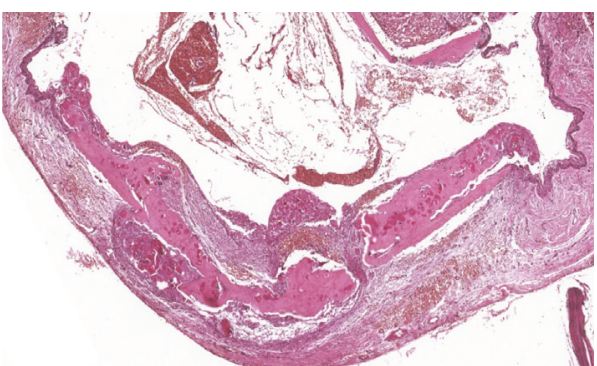

(d)

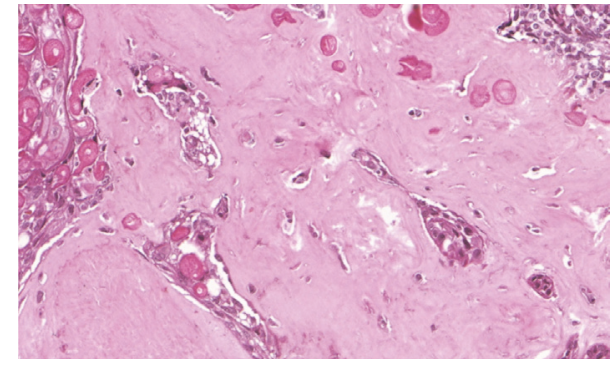

(f)

Figure 3: (a) Photomicrography showing a cystic lesion with a fibrous capsule and a lining of odontogenic epithelium (H/E, 40x). (b-c) Highlight for the columnar basal cells of similar to ameloblasts and the overlying layers loosely arranged with several amounts of ghost cells (H/E, 200x). (d-f) Extensive areas of eosinophilic matrix compatible with dentinoid within the fibrous capsule adjacent to odontogenic epithelium (H/E, 200x, 400x).

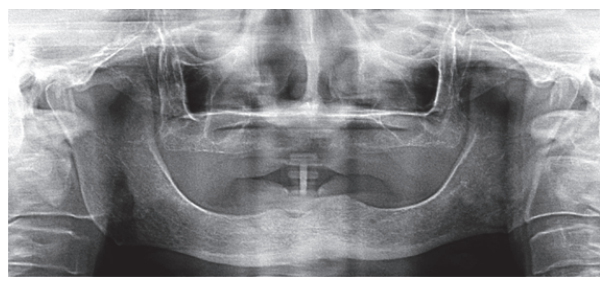

FIGURE 4: Panoramic radiography revealing bone neoformation after 6 months of the surgical procedure.

Approximately $65 \%$ of all cases of COC are reported in the anterior region of the mandible [14]. This study presents a case diagnosed in a 70-year-male patient that had a localized lesion in the anterior region of the mandible, similar features to the most frequent clinical and radiographic findings in the literature. COC may be associated with other odontogenic lesions, especially to odontomas (ranging from $22 \%$ to $47 \%$ ), ameloblastomas, adenomatoid odontogenic tumors, and ameloblastic fibromas [15]. In our study, there was no association of the cyst with another odontogenic lesion.
The histopathological findings of the COC include basal layer of the epithelial lining presenting a columnar or cuboid appearance with a similar appearance to ameloblasts. It is also possible to observe a cellular arrangement that resembles the stellate reticulum of the enamel organ in the suprabasal layers $[9,14]$. A significant feature of this lesion is the presence of anucleated and slightly eosinophilic cells, which are denominated "ghost cells." Displasic dentin also is present in the fibrous capsule [10, 13]. 
In the present case, it was possible to observe a prominent and extensive presence of dentinoid in the fibrous capsule. There are different theories regarding the etiology of this material; while some authors believe that it may be a result of an inductive effect by the odontogenic epithelium on the adjacent mesenchymal tissue $[10,11]$, others suggest it may be originated from ghost cells $[10,13]$. Fregnani et al. [16] also found some lesions with extensive areas of dentinoid in a histological and immunohistochemical evaluation of ten cases of COCs. This characteristic was observed in three cysts; two of them were associated with odontomas and the other was an extraosseous variant. In all the three cases, the representative dentinoid was located near the epithelium [16], what differs from the present study, in which the dentinoid extended from near the epithelium to deeper areas of the fibrous capsule. Furthermore, the literature shows that these areas of dentinoid commonly do not appear so extensive in COCs, as seen in the current case.

Intraosseous COC is mainly treated by enucleation, with a low rate of recurrence, occurring in $<5 \%$ of cases [8]. However, if this tumor is associated with another odontogenic tumor, the treatment and prognosis are likely to be same as for the associated tumor. There are reports of malignant transformation in recurrent cases of COC. Thus, long-term follow-up of such patients should be performed $[17,18]$.

In conclusion, the present case reinforces the importance of knowledge by the pathologists of the histopathological features of the intraosseous COC in order to achieve a correct diagnosis and, consequently, a favorable outcome for the patient. Furthermore, the literature shows that these areas of dentinoid commonly do not appear so extensive in COCs, as seen in the current case.

\section{Consent}

Written consent was obtained from the patient.

\section{Conflicts of Interest}

The authors declare that there are no conflicts of interest regarding the publication of this article.

\section{References}

[1] R. J. Gorlin, J. J. Pindborg, F. P. Clausen, and R. A. Vickers, "The calcifying odontogenic cyst-a possible analogue of the cutaneous calcifying epithelioma of Malherbe. An analysis of fifteen cases," Oral Surgery, Oral Medicine, Oral Pathology, Oral Radiology, and Endodontology, vol. 15, no. 10, pp. 1235-1243, 1962.

[2] L.-B. De Souza, M.-A. Gordón-Núñez, C.-F. Nonaka, M.-C. De Medeiros, T.-F. Torres, and G.-B. Emiliano, "Odontogenic cysts: Demographic profile in a Brazilian population over a 38-year period," Medicina Oral Patología Oral y Cirugía Bucal, vol. 15, no. 4, pp. e583-e590, 2010.

[3] N. R. Johnson, N. W. Savage, S. Kazoullis, and M. D. Batstone, "A prospective epidemiological study for odontogenic and non-odontogenic lesions of the maxilla and mandible in
Queensland," Oral Surgery, Oral Medicine, Oral Pathology, Oral Radiology, and Endodontology, vol. 115, no. 4, pp. 515-522, 2013.

[4] A. K. El-Naggar, J. K. C. Chan, T. J. Grandis Takashi, and P. J. Slootweg, Organization Classification of Head and Neck Tumours, World Health, Lyon, France, 2017.

[5] C. Ledesma-Montes, R. J. Gorlin, M. Shear et al., "International collaborative study on ghost cell odontogenic tumours: Calcifying cystic odontogenic tumour, dentinogenic ghost cell tumour and ghost cell odontogenic carcinoma," Journal of Oral Pathology \& Medicine, vol. 37, no. 5, pp. 302-308, 2008.

[6] J. M. Wright and M. Vered, "Update from the 4th Edition of the World Health Organization Classification of Head and Neck Tumours: Odontogenic and Maxillofacial Bone Tumors," Head \& Neck Pathology, vol. 11, no. 1, pp. 68-77, 2017.

[7] A. B. Urs, J. Augustine, H. Singh, K. Kureel, S. Mohanty, and S. Gupta, "Calcifying ghost cell odontogenic tumor (CGCOT) with predominance of clear cells: A case report with important diagnostic considerations," Oral Surgery, Oral Medicine, Oral Pathology, Oral Radiology, and Endodontology, vol. 121, no. 2, pp. e32-e37, 2016.

[8] A. Buchner, "The central (intraosseous) calcifying odontogenic cyst: an analysis of 215 cases," Journal of Oral and Maxillofacial Surgery, vol. 49, no. 4, pp. 330-339, 1991.

[9] M. Yoshida, H. Kumamoto, K. Ooya, and H. Mayanagi, "Histopathological and immunohistochemical analysis of calcifying odontogenic cysts," Journal of Oral Pathology \& Medicine, vol. 30, no. 10, pp. 582-588, 2001.

[10] S. Irani and F. Foroughi, "Histologic variants of calcifying odontogenic cyst: A study of 52 cases," Journal of Contemporary Dental Practice, vol. 18, no. 8, pp. 688-694, 2017.

[11] J. Sheikh, M. D. Cohen, N. Ramer, and A. Payami, "Ghost Cell Tumors," Journal of Oral and Maxillofacial Surgery, vol. 75, no. 4, pp. 750-758, 2017.

[12] E. R. Utumi, I. G. Pedron, L. P. N. da Silva, G. G. Machado, and A. C. Rocha, "Different manifestations of calcifying cystic odontogenic tumor.," Einstein (São Paulo, Brazil), vol. 10, no. 3, pp. 366-370, 2012.

[13] X. Zornosa and S. Müller, "Calcifying Cystic Odontogenic Tumor," Head \& Neck Pathology, vol. 4, no. 4, pp. 292-294, 2010.

[14] S. Kler, S. Palaskar, V. P. Shetty, and A. Bhushan, "Intraosseous calcifying cystic odontogenic tumor," Journal of Oral and Maxillofacial Pathology, vol. 13, pp. 27-29, 2009.

[15] A. Lucchese, M. Petruzzi, M. Scivetti et al., "Calcifying odontogenic cysts associated with odontomas: Confocal laser scanning microscopy analysis of 13 cases," Ultrastructural Pathology, vol. 35, no. 3, pp. 146-150, 2011.

[16] E. R. Fregnani, F. R. Pires, R. D. Quezada, I. M. Shih, P. A. Vargas, and O. P. De Almeida, "Calcifying odontogenic cyst: Clinicopathological features and immunohistochemical profile of 10 cases," Journal of Oral Pathology \& Medicine, vol. 32, no. 3, pp. 163-170, 2003.

[17] S. Mokhtari, Z. Mohsenifar, and M. Ghorbanpour, "Predictive Factors of Potential Malignant Transformation in Recurrent Calcifying Cystic Odontogenic Tumor: Review of the Literature," Case Reports in Pathology, vol. 2013, Article ID 853095, 6 pages, 2013.

[18] B. Tarakji, N. Ashok, I. Alzoghaibi et al., "Malignant transformation of calcifying cystic odontogenic tumour - A review of literature," Wspolczesna Onkologia, vol. 19, no. 3, pp. 184-186, 2015. 


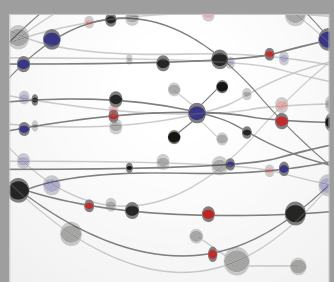

The Scientific World Journal
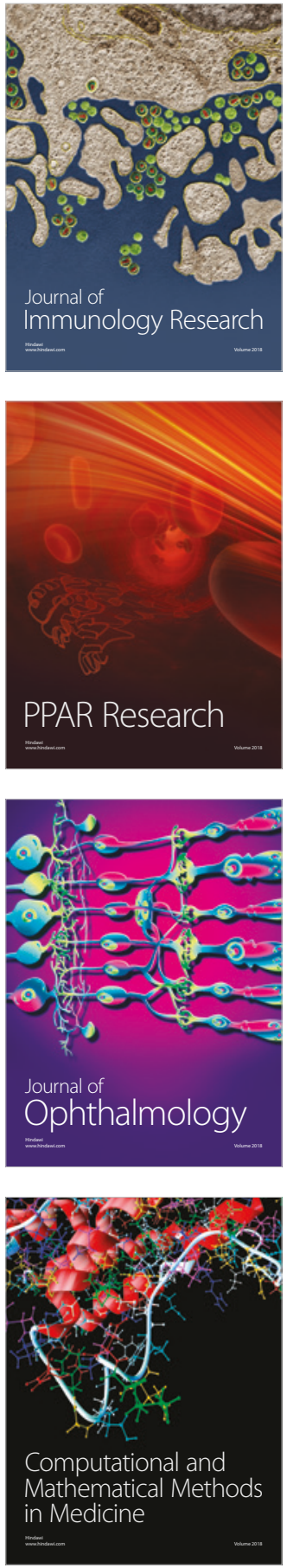

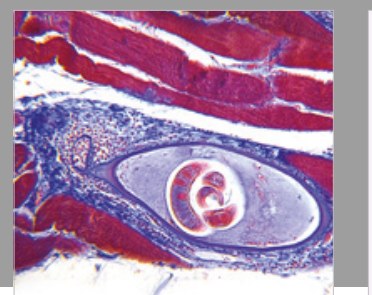

Gastroenterology Research and Practice

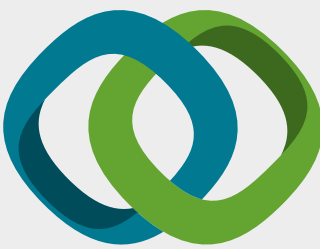

\section{Hindawi}

Submit your manuscripts at

www.hindawi.com
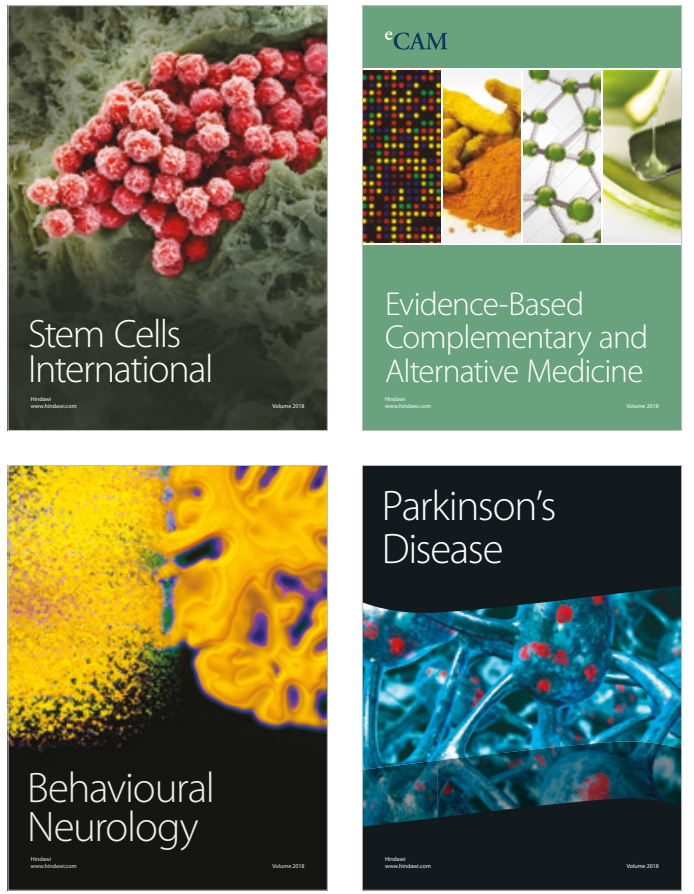

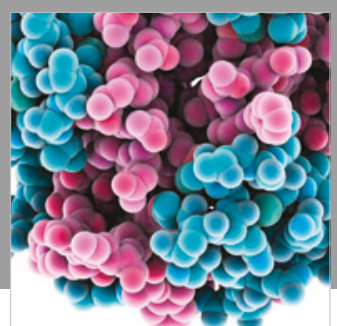

ournal of

Diabetes Research

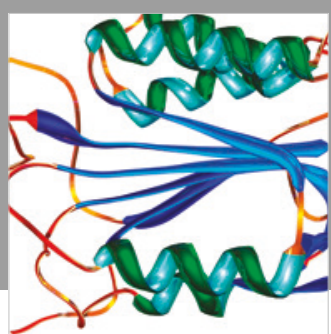

Disease Markers
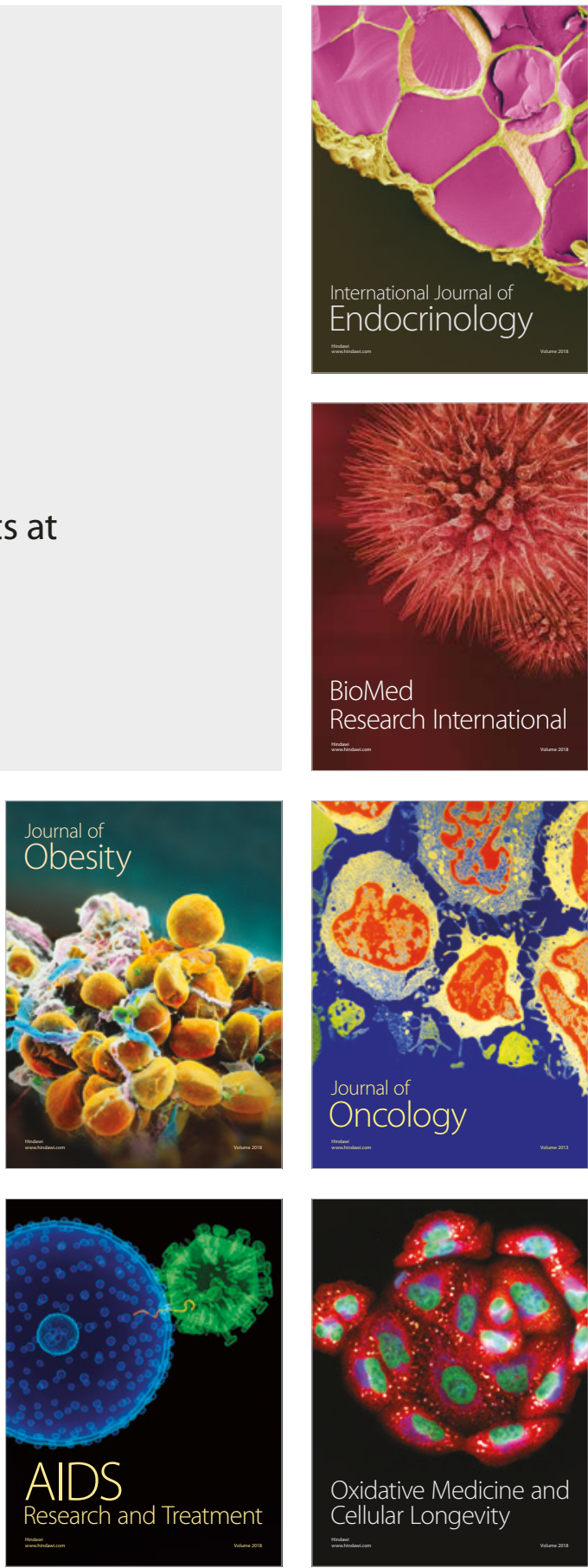